\title{
Structural evolution in a synthetically produced ultrafine grained low carbon steel
}

\author{
Priyanka Sharma $^{1} \cdot$ Ayushi Khandelwal $^{1} \cdot$ M. K. Banerjee ${ }^{2}($ )
}

(c) Springer Nature Switzerland AG 2019

\begin{abstract}
In this work, low carbon of extremely fine grain structure was produced by mechanical alloying of powders of iron and activated charcoal with minor addition of copper (Cu); mechanically alloyed powder was consolidated by spark plasma sintering to obtain a high-density compact. The steel so produced was subsequently subjected to forging followed by normalizing. The characterization was carried out by means of nanoparticle size analyzer, $\mathrm{X}$-ray diffraction, optical microscopy, scanning electron microscopy, transmission electron microscopy, and Vickers microhardness testing. The microhardness value obtained for the steel was found to be significantly high and comparable with that of nanocrystalline/ultrafine grained steels produced by other routes. The increased hardness resulted from the smaller grain size and presence of finely dispersed ultra small sized copper and cementite precipitates.
\end{abstract}

Keywords Fine grained ultra high hardness steel · Mechanical alloying · Grain growth inhibitor · Spark plasma sintering · Precipitation · Activated charcoal

\section{Abbreviations \\ HEBM High energy ball milling \\ AC Activated carbon \\ SPS Spark plasma sintering \\ MA Mechanical alloying}

\section{Introduction}

In the present age of energy economy, lightening of structural components and vehicles without detriment to its' functionalities has been a matter of great scientific interest. Development of new high strength materials with capability of being intricately shaped has been a major technological concern. In the domain of metals and alloys such requirement is generally met by suitable micro structural engineering. As a fallout, a surge in appearance of research reports on the design and development of ultra high strength steels of high fabricability can be noticed in recent literatures [1, 2]. Processing-structure-property co-relation of high strength lean alloy steels are studied by previous workers [3]. In view of the ability of ultra fine grained steels to achieve excellent combination of strength and toughness, there has aroused a great interest in scientific community for developing novel ultra fine structured steels [4]. Majority of researchers have aimed at evolving newer means to reproducibly manufacture second phase strengthened nanograined steels and as well as, gaining insight into the underlying physical sciences. Continued effort to tailor strategy for toughening and strengthening of ultra fine grained steels encompasses employment of different processing routes like thermomechanical processing $[5,6]$, severe plastic deformation by equal channel angular pressing $[7,8]$, cyclic quenching [9], dynamic strain induced transformation [10-12], roll bonding [13, 14], bidirectional large scale deformation and dynamic recrystallization through multi axle forging [15-17] for the production of ultra fine grained steels. These processes enable to achieve excellent combination of strength and ductility; accordingly, structurally refined

M. K. Banerjee, mkbanerjee@hotmail.com | 1 Department of Metallurgical and Materials Engineering, Malaviya National Institute of Technology, Jaipur 302017, India. ${ }^{2}$ Malaviya National Institute of Technology Jaipur, Jaipur 302017, India. 
steels of various types are seen to have assumed considerable commercial importance [18].

However, stabilizing the nanograined structure produced by any of the above mentioned techniques still remains a great scientific challenge. Ultra fine grain structure is associated with very high grain boundary area and hence high surface energy. Thermodynamic dictates to seek for an energetically favorable configuration induces a strong tendency for grain coarsening. The competitive process of grain refining by suitable processing in one end and the urge for lowering of overall free energy by means of grain coarsening on the other, goes to dynamically equilibrate the system to a limiting grain size. Inhibiting grain boundary movement by providing extremely small second phase particles concurrent with the grain refining activity may possibly be a good strategy to harness full grain refining capability of a processing technique.

It is known that mechanical alloying (MA) accomplished by high energy ball milling produces nano-scale alloy powders of extra ordinarily fine microstructure. Consolidation of the product by techniques like spark plasma sintering (SPS), hot isostatic pressing (HIP), vacuum hot pressing etc. can give ultrafine structured materials of excellent mechanical properties in complex shapes. In the light of observation made in the preceding paragraph, it appears that there lies a good potential to produce nanograined steels by synthesizing fine iron powder with elemental carbon in fine form. There are research reports on controlled ball milling of iron powder with carbon nanotubes to produce nanocomposite of excellent physical and mechanical properties $[19,20]$. In most of the reports on High Energy Ball Milling (HEBM) of transition metal - multiwall carbon nanotube (MWCNT), excellent interfacial bonding could be secured due to the presence of vacant $3 \mathrm{~d}$ orbital in transition metal which aids in $3 d-2 p$ hybridization to produce a good interfacial bonding. Another interesting effect of high energy ball milling of transition metal-carbon nanotube mixture is that the iron particles are heavily deformed due to harsh milling condition. It produces a high dislocation density in iron crystals. The interaction of these dislocations with the carbon atoms in outer layers of MWCNT played a decisive role in securing good interfacial bonding and hence excellent properties. Most of these work $[21,22]$ attempted to preserve the MWCNT structure such that the maximum benefit from its unique property may be duly accrued; therefore the works were focused on the study of structural and mechanochemical synthesis behavior of metal-CNT nanocomposite. A recent report on an attempt to synthetically produce nanograined steel by high energy ball milling of iron powder with MWCNT suggests that addition of nanosized copper particles may be a meaningful strategy to fully retain the benefit of possible refining action of ball milling. Since copper is not soluble in BCC iron, there remains the scope for elemental copper nanoparticles to be present in the structure and to inhibit the movement of grain boundary. The authors demonstrated that ultra fine grained steel with fine dispersion of partially destroyed MWCNT within ferrite could be produced successfully and that the steel yields a high hardness [23]. In the light of above it appears prudent to study the feasibility of producing nanograined steel by mechanical alloying of iron powder with an easily dissolvable form of carbon, such as, activated charcoal (AC). It is anticipated that top down approach of mechanical alloying will refine the activated charcoal to much smaller size and mechanochemical synthesis of iron and carbon can take place at ease. The copper nanoparticles are used as grain growth inhibitors.

Therefore the current research contemplates to study the feasibility of synthetically producing nanograined steel of high hardness. The synthesis is carried by mechanical alloying of iron, activated charcoal and copper powder followed by consolidation of product alloy powder with the aid of spark plasma sintering (SPS). Structural Characterization was done by XRD, optical, scanning and high resolution transmission electron microscopic study. Finally it attempts to understand the reasons behind the evolved microstructure and the attained hardness properties.

\section{Experimental procedure}

$39 \mathrm{~g}$ of Fe powder ( $\geq 99 \%$ purity) and Cu powder (by 0.4 wt\%) was ball milled using Fritsch Pulverisette-P6 high energy planetary ball mill with tungsten carbide vial and balls. The ball-to-powder mass ratio was maintained as 10:1 and toluene was used as a process control agent (PCA) to avoid excessive cold welding and also to protect the powder from oxidation. Rotational speed of disc was $400 \mathrm{rpm}$ and that of vial was $728 \mathrm{rpm}$. Powder samples were taken out after 1, 10, 20 and $30 \mathrm{~h}$ of milling to confirm the state of alloy formation. After $30 \mathrm{~h}$ of milling the powder was finally taken out for subsequent milling with activated charcoal (AC). 0.15 wt $\%$ of AC was added to the above Fe-Cu alloy powder mixture and mechanical alloying was carried out. High energy ball milling was carried out for $5 \mathrm{~h}$ with rotational speed of $300 \mathrm{rpm}$ for the disc. The as-milled powder was consolidated by Spark Plasma Sintering (SPS) in a $20 \mathrm{~mm}$ inner diameter graphite die at $800^{\circ} \mathrm{C}$ for $10 \mathrm{~min}$ under $50 \mathrm{MPa}$ axial pressure and cooled rapidly to room temperature. The sintering cycle is as shown in the Fig. 1.

Open die forging of SPS samples was carried out at $900^{\circ} \mathrm{C}$ after $30 \mathrm{~min}$ soaking at that temperature. In order to get rid of probable oxidation, the samples were coated with lime. No lubricant was applied as a subsequent rolling 
Fig. 1 Sintering cycle for spark plasma sintering (SPS) of as milled powder alloy

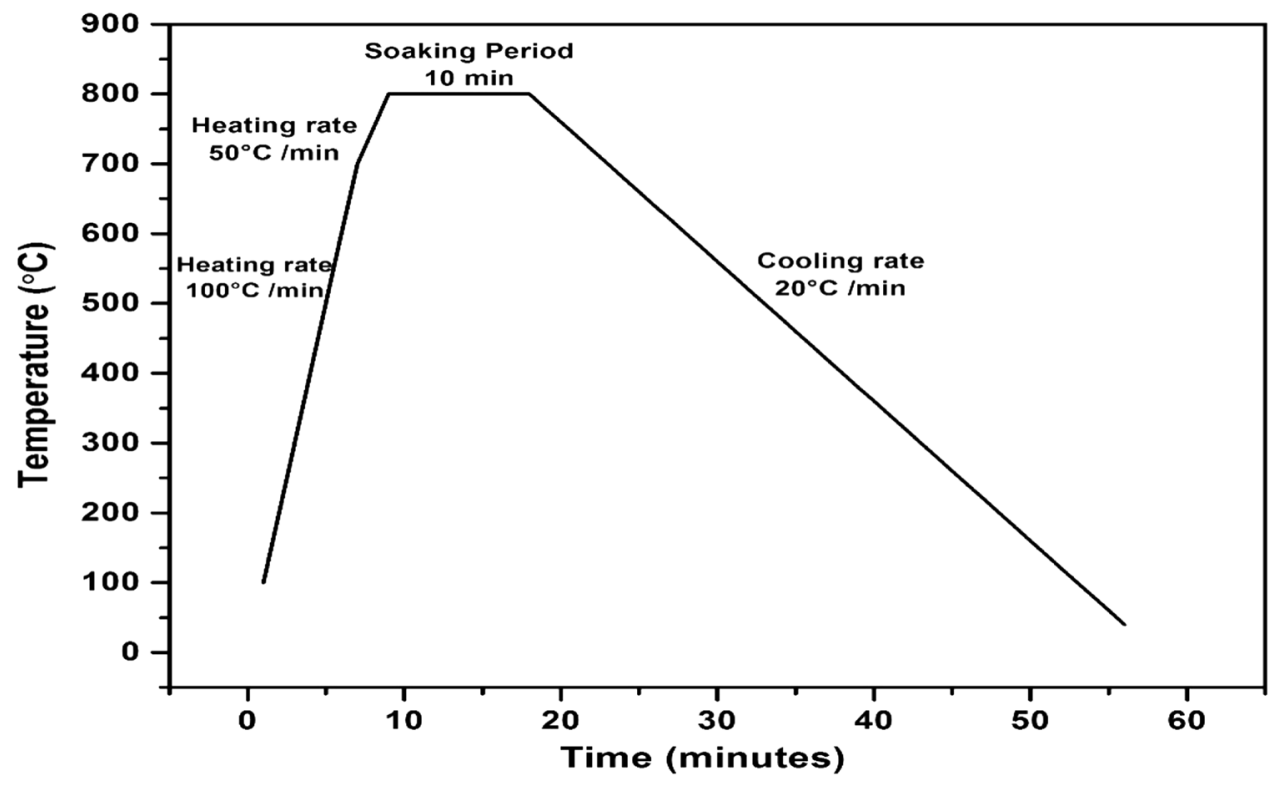

operation was due. The forging was done without any change in compression direction and there was no perceptible bulging; a $6.5 \mathrm{~mm}$ thick cylindrical sample of $20 \mathrm{~mm}$ diameter was reduced to a $3 \mathrm{~mm}$ thick cylinder with due enlargement in diameter. The calculated strain rate used for forging was $10 \mathrm{~s}^{-1}$. The samples were forged four times and the inter-stroke period was kept 5-7 min, during which the samples were kept in muffle furnace at the same temperature. In each stroke, the samples were given more than $15 \%$ reduction in thickness to ensure complete recrystallization. In fact for such a steel the recrystallization temperature is around $625^{\circ} \mathrm{C}$. Therefore, harmonious to previous report [24], the amount of deformation per pass $(>15)$ is supposedly capable to effect recrystallization. The procedure was continued until the thickness was reduced to $3 \mathrm{~mm}$ (>50\% reduction). The samples were then normalized at $850^{\circ} \mathrm{C}$ for $30 \mathrm{~min}$.

Nova Nano FE-SEM 450 was used to determine the particle size of as received iron powder (Fig. 2). The size of $\mathrm{Cu}$ particles was determined by nanoparticle size analyzer by suspending $\mathrm{Cu}$ in Propan-2-ol. The particle size and shape of AC was confirmed by using TEM (Tecnai G220 FEl). The sample was taken in a beaker filled with ethanol and then sonicated for $45 \mathrm{~min}$. The sample was collected from the top part of the ethanol and then spread on the top surface of carbon-coated Cu grid (200 mesh).

XRD was used for structural analysis of different powder samples as well as the final normalized sample. XRD was conducted by using X'Pert Pro Panalytical at $40 \mathrm{kV}$ and $40 \mathrm{~mA}$. It used $\mathrm{Cu} \mathrm{Ka}$ radiation with a wavelength of $1.54060 \AA$ A. Powder samples were placed on a glass holder and scanned from $20^{\circ}$ to $90^{\circ}$. All the major compounds of iron were covered by this scan range. The scanning rate

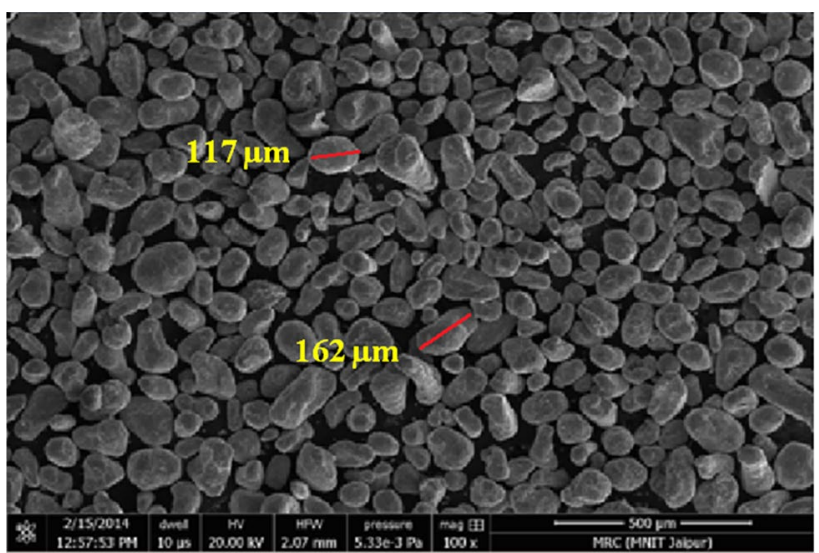

Fig. 2 SEM image of iron powder as received

was $2.0^{\circ} / \mathrm{min}$. The following equations were used to calculate the variation in lattice parameter during mechanical alloying:

$\lambda=2 \mathrm{~d} \sin \theta$

$d=\frac{a}{\sqrt{h^{2}+k^{2}+l^{2}}}$

Optical microscopy, Scanning Electron microscopy (SEM) and Transmission electron microscopy (TEM) were performed for microstructural analysis of final bulk sample. Normalized samples were ground, polished and etched with $2 \%$ nital for microstructural examination in optical microscope and scanning electron microscope (SEM). To prepare samples for TEM, the samples were first thinned to a thickness of below $60 \mu \mathrm{m}$. Standard discs of $3 \mathrm{~mm}$ were then punched from the samples. To make the samples 
Fig. 3 TEM images of as received activated charcoal $(\mathrm{AC})$
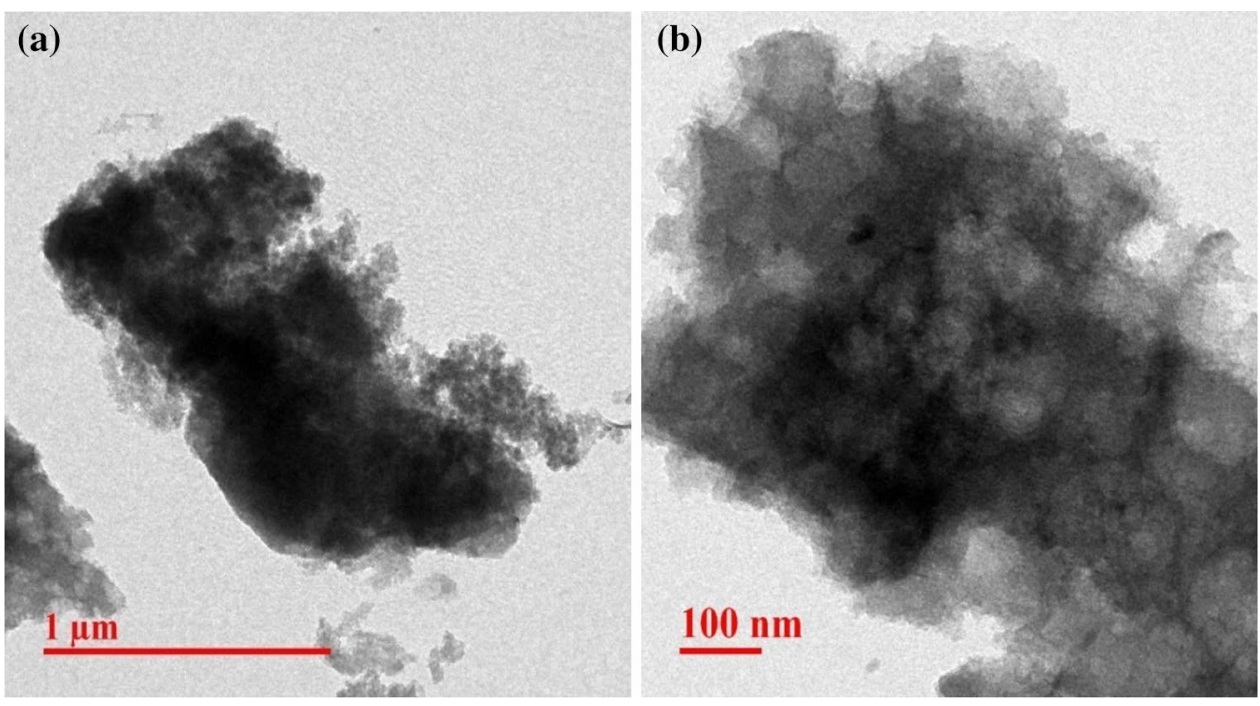

electron transparent, the samples were electro polished by a twin jet electrochemical polisher. The electrolyte consisted of $5 \%$ perchloric acid $\left(\mathrm{HClO}_{4}\right)$ in $95 \%$ ethanol and was kept at $-30^{\circ} \mathrm{C}$. TEM was carried out using Tecnai G220 FEl operated at $200 \mathrm{kV}$. Vickers Micro-hardness testing was carried out using Innova Test Nexus 4303to determine the hardness of normalized sample; $5 \mathrm{~g}$ load with a dwell time of $15 \mathrm{~s}$ were employed for measurement of hardness. The locations of indentations were around the centre of the sample. Care was taken to take each indentation separated from the neighboring one by at least 2.5 times the measured diagonal distance of an indentation so as to avoid mutual interference. Similarly edge effect was avoided by keeping the indentations well away from the sample edge. An average of 10 consistent readings was considered as the representative hardness of the sample. The standard deviation in hardness measurement was $\pm 3 \mathrm{HV}$.

\section{Results and discussions}

SEM image of as received iron powder is presented in Fig. 2. The particle size of as received iron powder was found to be $154.18 \pm 34.55 \mu \mathrm{m}$. It can be seen from the figure that iron powder was near spheroidal in nature. As shown in Fig. 3, TEM characterization of AC has confirmed its irregular shape and porous nature. Figure 4 represents the size distribution of copper particles. Particle size distribution of copper is found to be uniform with an average particle size of $833.2 \mathrm{~nm}$.

XRD pattern of Fe-Cu powder mix at different milling time is shown in Fig. 5. The XRD spectra in Fig. 5 reveal the peaks of a-ferrite which tend to broaden with increasing milling time. The broadening of ferrite peaks is presumably due to refinement of crystals and increase in lattice strain.

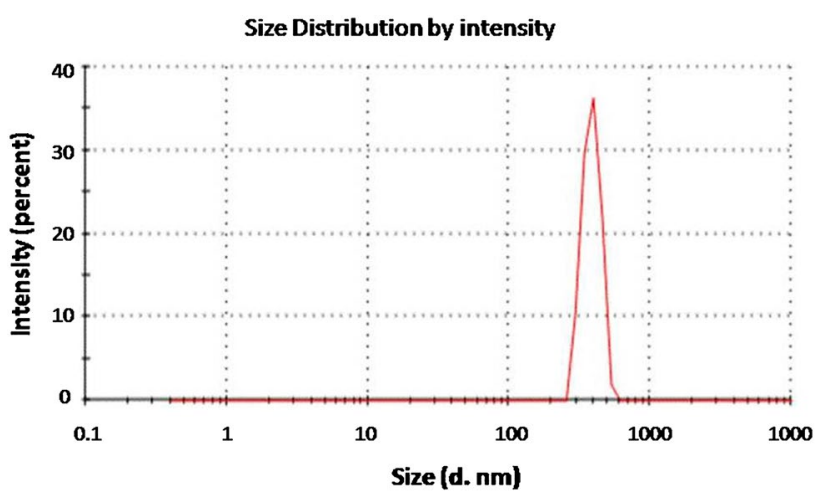

Fig. 4 Particle size distribution for Cu powder

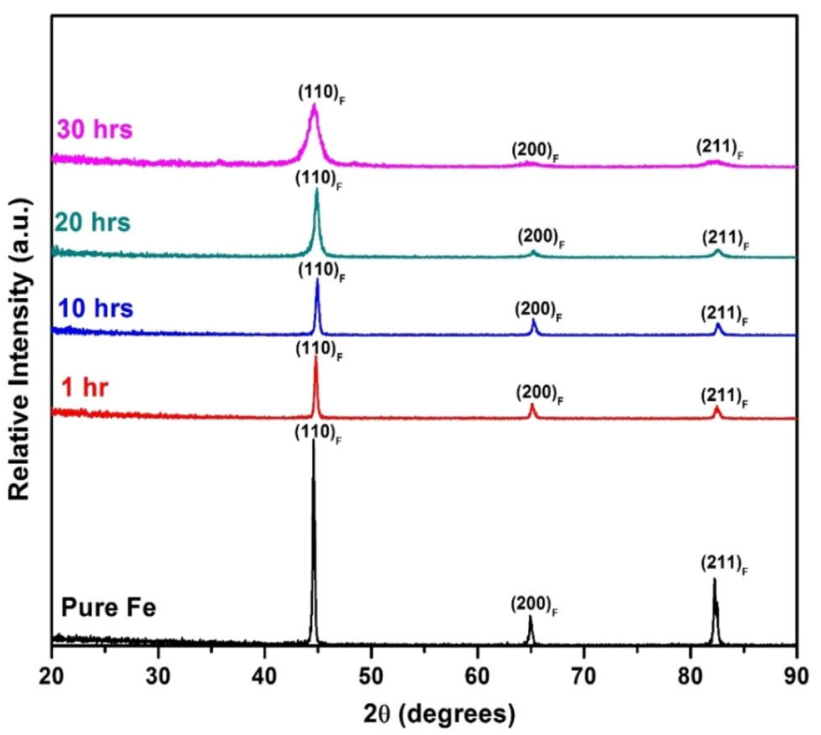

Fig. 5 XRD pattern of $\mathrm{Fe}+0.4 \mathrm{wt} \% \mathrm{Cu}$ as a function of milling hours. For comparison, XRD plot of pure $\mathrm{Fe}$ is also included. Here ' $\mathrm{F}$ ' corresponds to a-ferrite

\section{SN Applied Sciences}


Arguably, copper peaks should have been observed in the said spectra until a complete alloying is accomplished by high energy ball milling. However, in the present case, no such copper peak is discerned in the XRD spectra, even for low milling times, at which the completion of mechanical alloying is unlikely to take place. It seems that due to a very low concentration of copper in the milling mixture ( $0.4 \mathrm{wt} \%)$, the intensity of characteristic (111) peak of copper may become quite low; it is thus anticipated that the copper peaks lie below the detection limit in XRD and hence not discernible in the experimentally derived spectra. The measured lattice parameter as a function of milling time is shown in Fig. 6. The value of lattice parameter

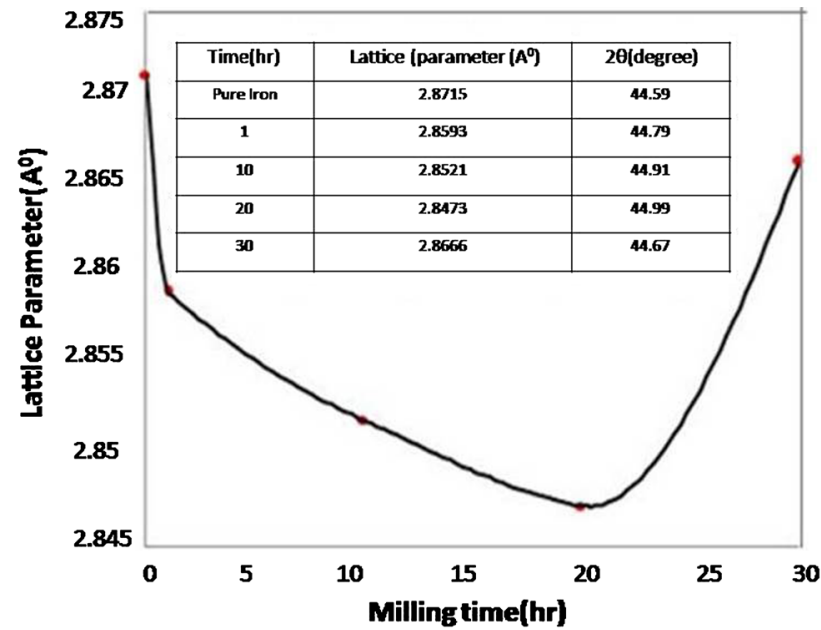

Fig. 6 Variation of Lattice Parameter as a function of milling time for $\mathrm{Fe}+0.4 \mathrm{wt} \% \mathrm{Cu}$ corresponding to each milling time is furnished in the table shown as inset of Fig. 6 . It is observed from Fig. 6 that the lattice parameter of iron decreases with increasing milling time. This is due to gradual dissolution of copper in iron with increasing milling time (till $20 \mathrm{~h}$ milling); beyond this milling time an increase in lattice parameter is noted. Although the equilibrium solubility of copper in BCC iron is extremely small, the high energy ball milling, a non-equilibrium processing technique, is capable of dissolving appreciable amount of copper in iron. The amount of dissolved copper should increase with milling time until certain limit. The atomic diameter of copper is less than that of iron. Thus substitution of copper atoms into iron lattice envisages diminution of lattice parameter as observed in Fig. 6 . The decrease in lattice parameter continues till $20 \mathrm{~h}$ of milling. Following this initial decrease, the lattice parameter increases if milling is carried out for $30 \mathrm{~h}$. At higher milling time, spontaneous rejection of copper could have taken place by strain induced mode of precipitation. However, it is difficult to establish this conjecture without a detailed investigation on this.

From the XRD spectrum of milled $\mathrm{Fe}+0.4 \% \mathrm{Cu}+0.15 \%$ AC sample in Fig. 7, the lattice parameter of (110) Fe is found to be $2.8721 \AA$. This value is higher than the measured lattice parameter of experimental iron powder which is $2.8715 \AA$. Apparently, the increase in lattice parameter is rather small; such increase in lattice parameter may be due to dissolution of carbon into iron crystals. As stated earlier, the chemically alloyed iron-copper (after $30 \mathrm{~h}$ milling) powder is mixed with activated charcoal and then subjected to HEBM for $5 \mathrm{~h}$. If the lattice parameter of iron in milled $\mathrm{Fe}+\mathrm{Cu}+\mathrm{AC}$ mixture is compared with that after
Fig. 7 XRD pattern of $\mathrm{Fe}+0.4 \mathrm{wt} \% \mathrm{Cu}+0.15 \mathrm{wt} \%$ AC after milling (in black) and after SPS (in red). Here 'F' corresponds to $a-f e r r i t e$ and ' $C$ ' to cementite

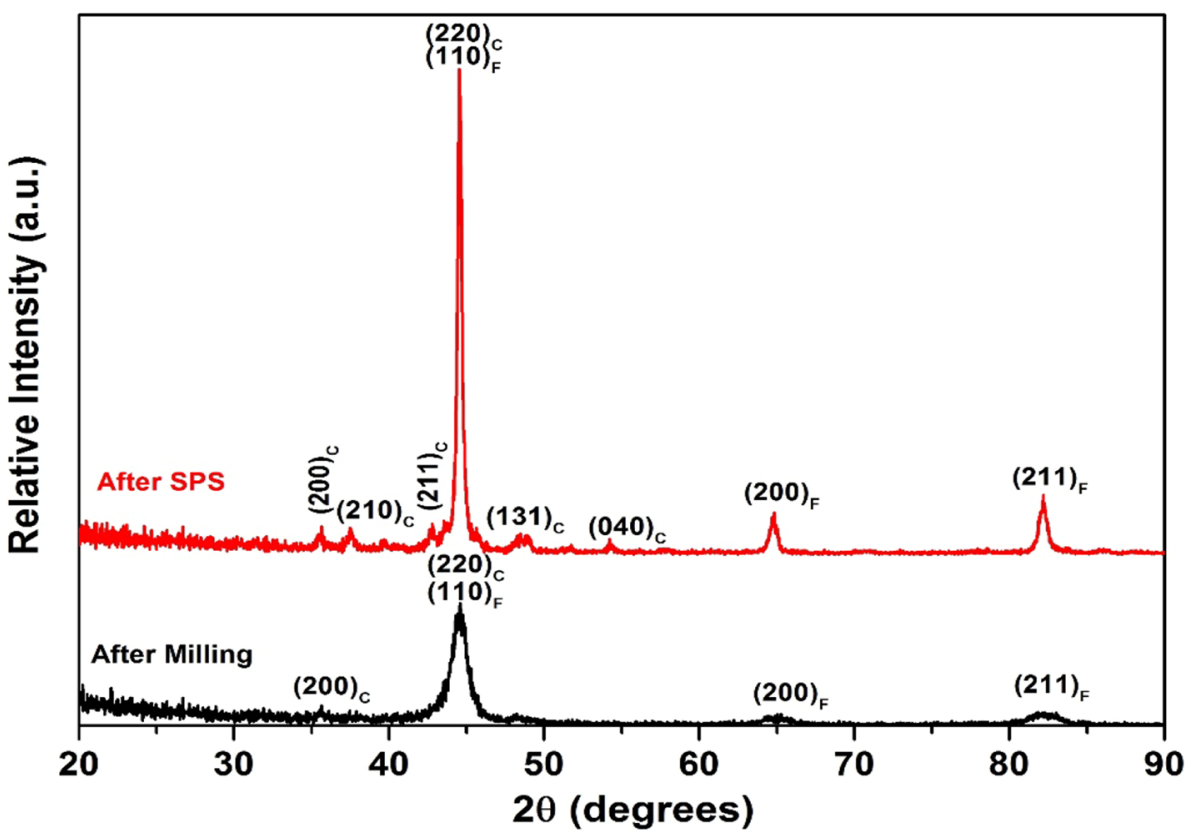

SN Applied Sciences 
$30 \mathrm{~h}$ milling of $\mathrm{Fe}+\mathrm{Cu}$ mixture (the starting point for milling with $\mathrm{AC}$ ), the increase in lattice parameter is found to be still higher $(2.8721 \AA$ against $2.8666 \AA$ ). This signifies that high energy ball milling of Fe-Cu alloy powder with $\mathrm{AC}$ for $5 \mathrm{~h}$ has led to considerable dissolution of carbon and hence the alloy formation.

After such milling for $5 \mathrm{~h}$, the powder is consolidated by spark plasma sintering. The XRD spectra of mechanically alloyed $\mathrm{Fe}+\mathrm{Cu}+\mathrm{AC}$ mixture before and after SPS are compared in Fig. 7. It is revealed that, after consolidation by SPS, the (110) peak of iron becomes much narrower. It is understood that SPS at elevated temperature may lead to both particle coarsening and residual stress relieving. Both these effects tend to reduce the line broadening effect and thus make the diffraction curve appear sharper (Fig. 7). Although the residence time at sintering temperature is rather small, the driving energy for particle coarsening is always very high for ultra small particles; hence, nanosized particles undergo considerable coarsening even for a small residence time of $10 \mathrm{~min}$ at SPS temperature.

It is noticed that cementite peaks appear in XRD spectra of both milled and milled + SPS sample and that the characteristic peaks of cementite become more intense after sintering. This is so because at the elevated temperature of SPS, the carbon atoms dissolved in iron in excess of equilibrium solubility limit, precipitate out in the form of cementite. Besides this, some extra peaks of cementite which were unseen in the XRD spectrum of the milled sample are seen to appear in the X-ray diffractogram of SPS sample (Fig. 7). This implies that SPS of HEBM samples tend to relieve super saturation of ferrite and leads to the formation of a greater amount of ultra-small sized cementite particles in ferrite matrix. After SPS, the lattice parameter of iron crystals is calculated to be $2.8739 \AA$. This lattice parameter is higher than the $\mathrm{Fe}+\mathrm{Cu}$ alloy and thus makes it evident that copper has also been precipitated out during spark plasma sintering. It may further be noted that this lattice parameter is marginally higher than that of pure iron (2.8715 $\AA$ ). This proves that some amount of carbon is still retained in solid solution in ferrite. The equilibrium solubility of carbon in iron at $650^{\circ} \mathrm{C}$ is around $0.020 \mathrm{wt} \%$. Therefore, the amount of carbon that was dissolved by ball milling in excess of its equilibrium solubility limit ( $0.02 \mathrm{wt} \%)$ would be precipitated as cementite during the time of holding at SPS temperature. After SPS, samples were cooled rapidly to discourage grain coarsening. The rapid post SPS cooling retains some dissolved carbon in BCC iron and hence the observed lattice parameter in sintered product is higher than pure iron.

When $0.15 \mathrm{wt} \% \mathrm{AC}$ is mixed with $30 \mathrm{~h}$ milled Fe-Cu alloy powder and then high energy ball milling is carried out for $5 \mathrm{~h}$, two events can occur. The usual mechano- chemical synthesis of iron and carbon can take place due to very high chemical affinity between iron and carbon; thuscementite $\left(\mathrm{Fe}_{3} \mathrm{C}\right)$ may form. However, carbon can equally dissolve in iron and can form interstitial solid solution (ferrite). Due to being a non equilibrium processing technique, HEBM may lead to dissolution of carbon in iron to a level in excess of the equilibrium solubility of carbon in iron. In fact equilibrium solubility of carbon in BCC iron is very small at room temperature $(0.007 \mathrm{wt} \%)$. However, it is known that supersaturation of iron by dissolved carbon is very much possible undera non-equilibrium situation viz. occurrence of martensitic or bainitic transformation. Degree of deviation from equilibrium is dependent upon its processing condition and there is no authentic data as yet, regarding the limit of supersaturation of ironby carbon under a situation of pressure induced dissolution. There is, therefore reason to understand that depending upon the aggressiveness of processing condition, pressure induced dissolution of carbon in BCC iron can have different limits of solubility. Excess carbon, if any, will undergo mechanochemical synthesis with iron to form iron carbide in very fine form. The second possible reason for appearance of carbide peaks in XRD spectrum of as milled sample may be that the ball milling energy is shared more by the iron particles due to high mass fraction. Thus iron particles get plastically deformed with generation of high density of dislocations. These dislocations act as the site for segregation of carbon atoms due to its' high interaction energy with carbon atoms [25]. The highly supersaturated iron partially gets relieved of supersaturation during post milling residence time. This phenomenon is akin to autotempering of martensite in high carbon steel where precipitation of cementite takes place in a fine form even when it is kept at room temperature for finite time. Instability of martensite is remarkably high in a high carbon steel and with the available mobility of carbon atoms at room temperature, precipitation of cementite may take place. This accounts for the presence of a small (002) peak of cementite in XRD spectrum of the ball milled alloy.

The microstructures of the samples after normalizing are shown in Fig. 8. The bright field optical micrograph in Fig. 8a reveals fine grained ferrite with dispersed second phase, supposedly, fine scale cementite particles. The fineness of ferrite grains owes its origin to the processing techniques. The crystal size in $\mathrm{Fe}+\mathrm{Cu}$ mixture became extremely small after $30 \mathrm{~h}$ milling. Further milling for $5 \mathrm{~h}$ with $0.15 \% \mathrm{AC}$ has been additive to the refining process. As discussed earlier, the alloy powder was comprised of extremely small nanosized ferrite crystals with dispersed copper and cementite particles. SPS has added to the number density of these particles for reason stated in previous paragraph. The prevailing particles of cementite and copper have acted in opposition to inherent coarsening traits of ultra small grains by way of acting 

$\mathrm{Fe}+0.4 \mathrm{wt} \% \mathrm{Cu}+0.15 \mathrm{wt} \% \mathrm{AC}$ at $1000 \times$, b in polarized light, and c SEM image of $\mathrm{Fe}+0.4 \%$ $\mathrm{Cu}+0.15$ wt $\%$ AC of normalized sample at 10,000x
Fig. 8 a Optical image of
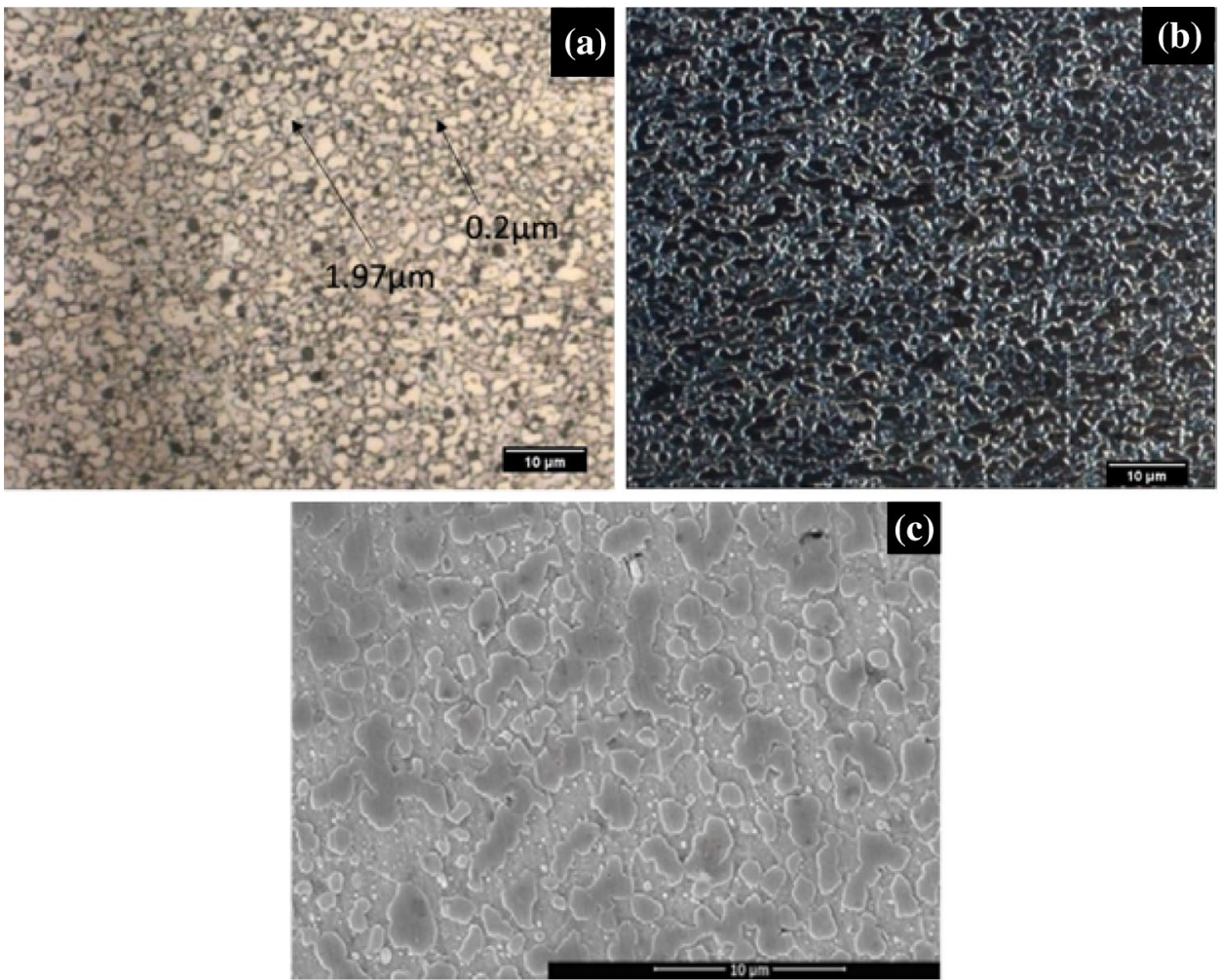

as barriers to grain boundary movement. During SPS, a rapid rate of heating to SPS temperature and fast cooling after short holding for 10 min at sintering temperature have also helped in retaining the fine grain size of ferrite. The same microstructure observed under polarized light does not discern any new microstructural feature. The microstructure is also examined under scanning electron microscope. The secondary electron image in Fig. 8c shows that the maximum size of grains lies below $2.9 \mu$ and that microstructure consists of ferrite and dispersed second phase particles. The exact grain size distribution however gives a clearer picture about the derived grain size in MA steel under study. The size ranges from 0.095 to $2.9 \mu \mathrm{m}$ is observed and the size of maximum number of grains lies within $0.5 \mu \mathrm{m}$ to $0.895 \mu \mathrm{m}$, the average being around $0.7 \mu \mathrm{m}$ (Fig. 9).

In order to gain a deeper understanding about the microstructural evolution in the experimental alloy, a detailed transmission electron microscopy is carried out (Fig. 10). Bright field image in Fig. 10a verifies that the finally achievable average grain size of alloy, synthesized by the present method can be quite low. The microstructure further reveals the presence of fine cementite particles within the ferrite grains; the presence of cementite spots can be noticed in the corresponding SAEDP, shown at the inset of Fig. 10b. This observation adds further credence to the proposition of cementite precipitation

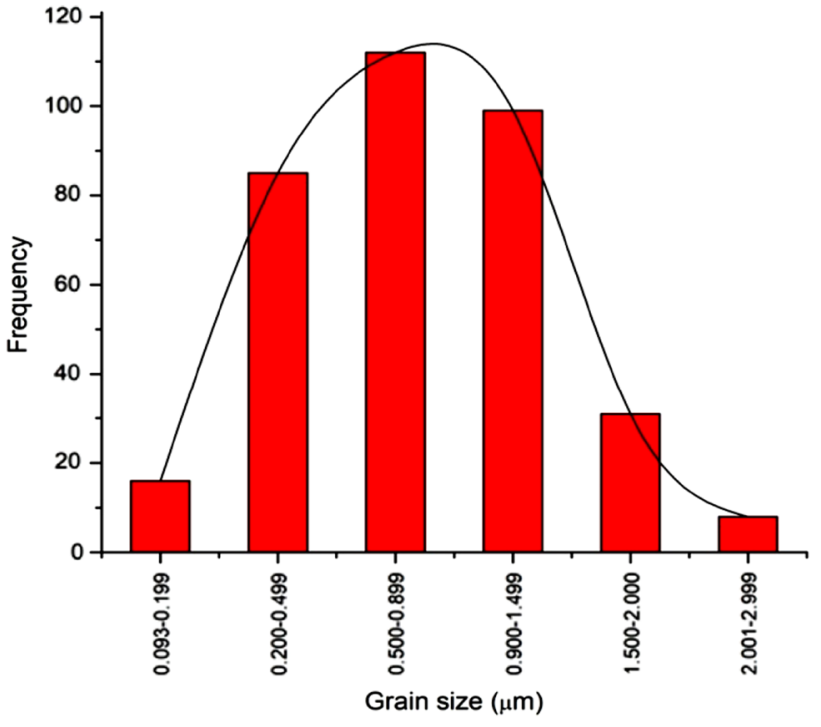

Fig. 9 Grain size distribution in mechanically alloyed steel

in the experimental alloy and hence lends support to the explanations furnished in preceding paragraphs.

The bright field image in Fig. 10b delineates the microstructural features within a grain of ferrite; it can be observed that fine round shaped precipitates are uniformly distributed throughout the matrix. Dislocations in the form of faint network are also observed in the same microstructure (Fig. 10b). Arrow marked region shows 

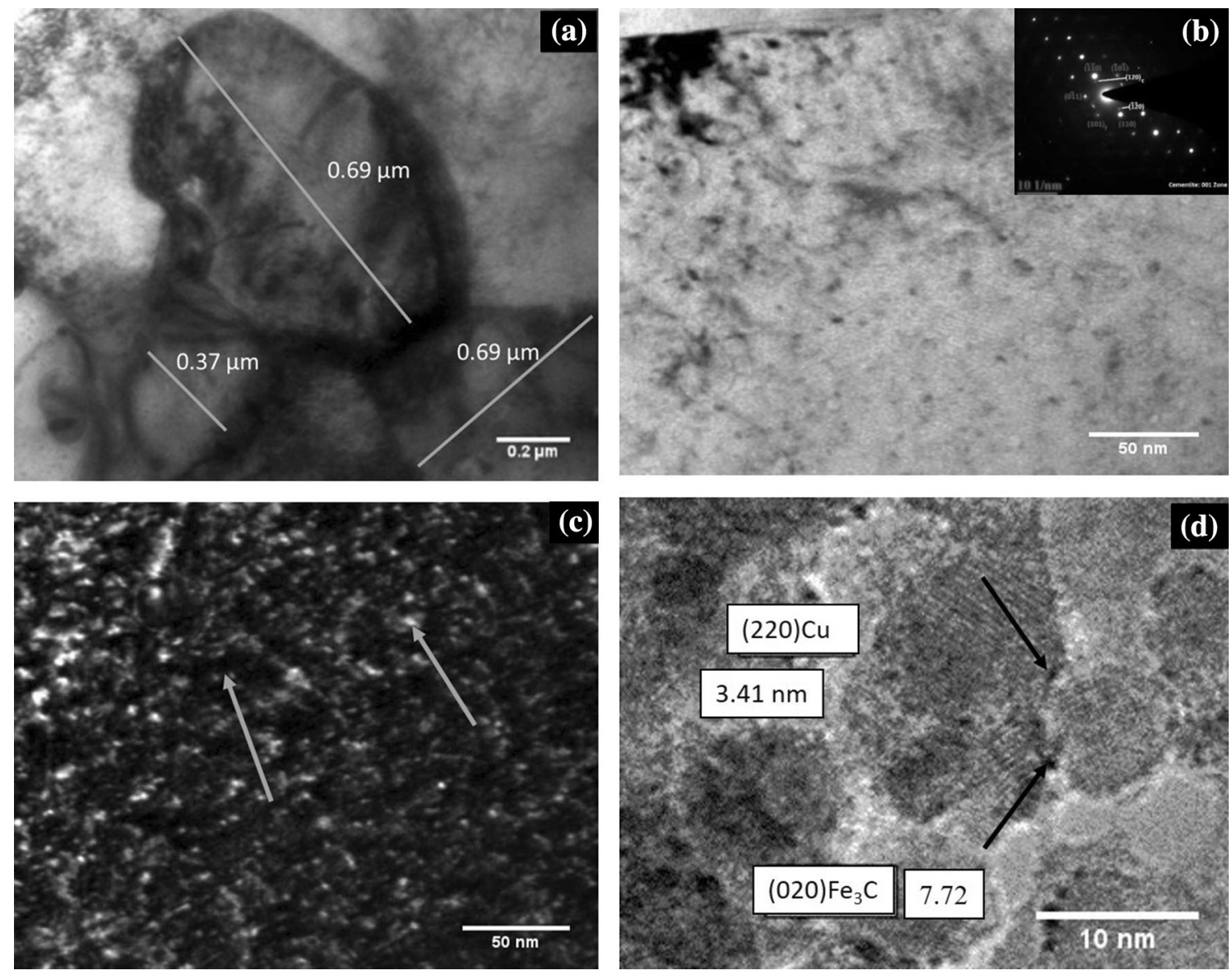

Fig. 10 TEM images of final sample of $\mathrm{Fe}+0.4 \% \mathrm{Cu}+0.15$ wt $\% \mathrm{AC}$ a image representing fine grains, $\mathbf{b}$ bright field image with an inset showing the corresponding diffraction pattern of $a$ - ferrite and

cementite, $\mathbf{c}$ dark field image, and $\mathbf{d}$ HRTEM imageshowing precipitates of $\mathrm{Cu}$ and $\mathrm{Fe}_{3} \mathrm{C}$

the precipitates segregated at dislocations. The pinning of dislocations by precipitates does not allow the annihilation of dislocations which proceeds through thermally activated processes. The corresponding dark field image aids in a better appreciation of structural evolution in the experimental alloy. As described earlier, high energy ball milling envisages substantial dissolution of carbon in iron; moreover, the iron crystals, after HEBM, contain high density of dislocations due to heavy plastic deformation. Heating to a temperature, $650{ }^{\circ} \mathrm{C}$ and holding there for $10 \mathrm{~min}$ during SPS, leads to the formation of dislocation arrays of low energy configuration; the precipitation of cementite particles takes place on the dislocation substructure so produced. The portion of copper dissolved in ferrite due to HEBM is likely to undergo segregation at the preexisting dislocation networks. These copper particles exert additional effect in favor of stabilization of dislocation sub structure. The dislocation structure is seen to persist even after partial dissolution of carbide and copper precipitates during the process of forging followed by normalizing.

When the material is cooled from the normalizing temperature, the dissolved carbon as well as copper undergoes precipitation at the grain and sub-grain boundaries. Since the solubility of copper in BCC iron is extremely small, most of copper are precipitated both intergranularly and intragranularly. The presence of precipitates within the sub-grains is clearly discerned in the dark field image in Fig. 10c. It is therefore apparent that apart from high degree of grain refinement accomplished by high energy ball milling, minor addition of copper has helped to restore the refining effect of high energy ball milling by restricting the grain boundary movement. The beneficial effect of copper persists even after normalizing. These dispersed copper and cementite particles have retarded inherent tendency for grain growth and hence a nanograined steel could be synthetically produced.

High resolution TEM image in Fig. 10d ascertains the presence of nanosized cementite and copper particles within the microstructure of the alloy. It is observed from the HRTEM image that the size of cementite particle is 
around $7.72 \mathrm{~nm}$ whereas the size of copper is $3.41 \mathrm{~nm}$ approximately. Moreover, it is evident from the HRTEM image (Fig. 10d) that the particle boundaries especially, those of the cementite particles are tethered by some kind of extremely small black particles (shown by the arrow). It has not been possible to exactly characterize these features. It is appropriate to surmise that these dots like entities are aggregation of a few carbon atoms. These carbon dots are seen in plenty and probably originates from the applied top down approach of continuous size reduction of AC powder through high energy ball milling. Disintegration of $A C$ is much aggravated in the present scenario in view of ball milling being carried out in presence of much higher amount of heavier and stronger iron powder.

The microhardness value of the synthesized nanograined steel is seen to be extremely high (Table 1). A value of as high as 541.3 VHN has been achieved for this newly developed steel; this hardness value is undoubtedly higher than many of the ultrafine grained steels reported to have been produced through different routes like accumulative roll bonding, equal-channel angular pressing etc. The high hardness value of this steel is ascribed to strengthening due to grain refinement (grain size $\sim 700 \mathrm{~nm}$ ) and precipitation strengthening by ultrafine cementite particles $(\sim 8 \mathrm{~nm}$ in size) uniformly dispersed within the matrix; moreover, the presence of nanoscale copper precipitates (of size $\sim 3 \mathrm{~nm}$ ) in the microstructure has insured additional precipitation strengthening. It is further envisaged that the novelty of this steel lies in formation of carbon dots whose functional ability in a steel is not known and warrants deeper scientific exploration. It is apparent that in spite of the existence of a highly conducive situation for strengthening of steel, it is very difficult to reconcile the factors responsible for such an unusually high hardness value of a low carbon steel with $0.4 \mathrm{wt} \%$ copper. The discovery of the presence of carbon dots tethering the second phase particles in the microstructure of the nanograined steel entices one to believe that besides aforesaid precipitation hardening and grain refinement, such enormous enhancement in hardness value of the experimental steel also owes a lot to some kind of interaction between carbon dots and strain field of dislocations.

Due to constraint of availability of sufficient amount of MA steel, it has not been possible to undertake a detailed study of mechanical properties. However, to examine the potential of this novel material, effort has been made to derive a qualitative idea of the possible strength properties of the alloy by computing the expected strength values from the existing sources of information about ultra fine grained steel as available in literature [27-40]. It is known that the yield strength of a precipitation hardenable alloy like the steel under discussion can calculated from the general equation. $\sigma_{\mathrm{ys}}=+\sigma_{\mathrm{i}}+\sigma_{\mathrm{ss}}+\sigma_{\mathrm{ph}+}+\mathrm{kd}^{-1 / 2}\left(\sigma_{\mathrm{i}}\right.$ being friction stress and $\mathrm{k}$ is a constant that represents the strength of grain boundary and $\sigma_{s s^{\prime}} \sigma_{\mathrm{ph}}$ being the respective contributions from solid solution and precipitation strengthening.

After a critical analysis of data available from the results of previous researches on the strength and grain size of ultrafine grained steels, Ravi Chandran has demonstrated that Hall-Petch equation in its classical form, i.e. $\sigma_{\mathrm{ys}}=\sigma_{\mathrm{i}}+\mathrm{kd}^{-1 / 2}$ ( $\sigma_{\mathrm{i}}$ being friction stress and $\mathrm{k}$ is a constant that represents the strength of grain boundary) does not hold good at extremely small grain size regimes [27]. Fitting the experimental results from various sources into the frame of classical Hall-Petch equation without regard to contribution from other strengthening parameters, it was revealed that different values of $\sigma_{i}$ and $k$. ( $\sigma_{i}$ ranges from 25 to $89 \mathrm{MPa}$ and $\mathrm{k}$ from .39 to $.77 \mathrm{MPa} \mathrm{m}^{1 / 2}$ ) are obtained for various ranges of grain size. It is known that the strengthening due to grain refinement is explained by dislocation pile up or dislocation source mechanisms as postulated earlier $[28,29]$. Taking all these things in consideration and keeping the different experimental data in consideration, Ravi Chandran has proposed a new equation, $\sigma_{\mathrm{ys}}-\sigma_{\mathrm{i}} /$ $\sigma_{s}-\sigma_{i}=\exp \left(-C d^{1 / 3}\right)$ to describe effect of grain size on the yield strength of ultrafine grained steels; this equation is found capable to accommodate more than $90 \%$ of experimental data at specific value of $C \sim 2.52 \mu \mathrm{m}^{1 / 3}$. Here $\sigma_{\mathrm{s}}$ and $\sigma_{i}$ denotes the maximum and minimum attainable yield strength due to grain size effect; upon consideration of stress requirement for dislocation creation within a small grain for yielding to start as $\sigma_{s}$ and yield strength for a single crystal of infinite size as $\sigma_{i}$, one gets the corresponding values of $\sigma_{s}$ and $\sigma_{i}$ as $5733 \mathrm{MPa}$ and $50 \mathrm{MPa}$ respectively.

Figure 9 describes the grain size distribution derived in the present study; using the average grain size, $700 \mathrm{~nm}$, in Ravi Chandran's equation, the potential yield strength

Table 1 Comparison of hardness of forged sample with other submicron grained steels

\begin{tabular}{llll}
\hline Production route & Hardness (HV) & References \\
\hline Accumulative roll bonding (ARB) process [hardness due toultra fine ferrite grains along with & 318 & \\
solid solution and precipitation hardening] & 240 & [26] & \\
Equal-channel angular pressing (ECAP) [hardness of ultra fineferrite phase] & $541.3 \pm 3$ (SD) & [8] \\
Powder metallurgy & Present study \\
\hline
\end{tabular}


of the experimental material turns out to be $656 \mathrm{MPa}$. Instead, if the average grain size data is used in classical HP equation taking $\sigma_{i}$ and $k$ values as $50 \mathrm{MPa}$ and $0.55 \mathrm{MPa} \mathrm{m}^{1 / 2}$ respectively (the midway values of the range into which previous experimental data fall), it is found that the synthesized steel can have a possible yield strength value of $707 \mathrm{MPa}$. However, the structural situation in present study is quite different from the previous studies. In contrast, if the maximum possible values of $\sigma_{i}$ and $\mathrm{k}$ ( $89 \mathrm{MPa}$ and $.77 \mathrm{MPa} \mathrm{m}{ }^{1 / 2}$ respectively) are taken to calculate the yield strength of experimental steel, this gives rise to the YS value of $1245 \mathrm{MPa}$, which seems plausible for steels with grain size lying within $500-1000 \mathrm{~nm}$.

Moreover, Bouaziz has elegantly studied the grain size effect on strength and ductility of ferritic steel over a wide range of grain size from $80 \mathrm{~nm}$ to 80 microns. These data qualitatively described that ductility decreases with grain size while there is a simultaneous increase in yield strength [30]. Massart et al. modeled the data due to Bouaziz with the help of strain gradient plasticity based finite element technique and derived the conclusion that there is loss in ductility due to grain refinement [31]. It is demonstrated elsewhere $[27,31]$ that dislocation activities become limited as the grain size decreases to below $200 \mathrm{~nm}$ and that there is a limiting grain size below which grain boundary sliding dominates the deformation mechanism; this represents the saturated yield strength and for a further grain refinement below the critical grain size, inverse HP behavior is exhibited. While varying values of critical grain size (from $10 \mathrm{~nm}$ till $100 \mathrm{~nm}$ ) for YS saturation is advocated by different scientists [27, 31, 32, 34], the presently developed steel possesses an average grain size $(\sim 0.7 \mathrm{~nm})$ where dislocation activities are operative and hence Hall-Petch type relation is applicable. Taking Bouaziz's results into consideration, the model of Massart et al. has predicted a relation between yield stress (at $0.2 \%$ plastic strain) as a function of $1 / \sqrt{ } d$. If the possible yield stress of the present steel is computed from this relationship, a value of around $650 \mathrm{MPa}$ is resulted.

The predicted strain of the steel as obtained from the earlier report due to Massart et al. is 0.05; when computed from nominal stress- strain curves for different grain sizes of ferritic steels [31] the yield stress of experimental steel is found to be estimated to a figure close to $0.9 \mathrm{GPa}$. The concordant results provided by the investigation due to Hidaka et al. [32] adds further credence to the present observations. The different values computed from different considerations make the authors surmise that for the synthesized steel, the attainable maximum yield strength due to grain size effect is around $1.1 \mathrm{MPa}$.

It is demonstrated that in case of carbon steel produced through mechanical alloying route, the hardening due to solid solution is rather small and major hardening comes from grain refinement. Such strengthening was seen to continue till $100 \mathrm{~nm}$ grain size below which grain boundary sliding came into play and thus HP relation breaks down. For reasons stated above, the effect of solid solution strengthening is ignored in the calculation of yield strength from the measured hardness value.

In addition, a failure analysis of white structure flaking in wind turbine gear box due to Evans has delineated that ferrite of $10-50 \mathrm{~nm}$ size is formed in the surrounding region [33]; Evans proved that carbon due to its poor solubility in ferrite is segregated in high concentrations at the nanograin boundaries which are composed of densely populated dislocations. Besides, the formation of carbon vacancy complex cannot be underestimated. These results are suggestive of strength increment in nanograined steel along with its propensity to exhibit intercrystalline failure and hence a poor ductility. This corroborates the ductility value of the experimental steel as predicted in preceding paragraph.

Previous studies due to Kimura et al. has shown that increasing milling time during mechanical alloying (MA) by high energy ball milling enhances the Vickers hardness of ferritic steel due to both grain refinement and work hardening $[34,35]$. Continued milling increases the dislocation density at the boundaries of dislocation cells and thus, increases the angle of misorientation across the boundaries that leads to creation of high angle grain boundary. Ultimately MA can produce grain size up to $10 \mathrm{~nm}$ with its hardness of HV 1900. It is also observed in the same study that the softening of mechanically alloyed material due to annealing for $5 \mathrm{~h}$ is slow at lower temperature, whereas, it becomes faster at temperature above $900^{\circ} \mathrm{C}$. In consideration of the milling time used in the present study, the experimental alloy should, according to the observation of Kimura et al., exhibit a hardness of HV 850; however the final hardness of HV 536 obtained in the present study is attributed to the annealing effect experienced in the present study; this has led to a decline in hardness by about HV 300 and is in agreement with the earlier results on annealing of nanograined steel [34].

Following the observation that Vickers hardness number of iron and steel is three times the ultimate tensile strength (UTS) of iron and steel (in $\mathrm{kg} / \mathrm{mm}^{2}$ ), the UTS of our steel should be around $179 \mathrm{~kg} / \mathrm{mm}^{2}-1.8 \mathrm{GPa}$ [34]; the UTS achievable in a steel is known to be the sum of the yield strength and strain hardening effect. Thus it is conjectured that the steel synthesized by the authors is of ultrahigh strength type with an UTS value of no less than 1.8 GPa.

Moreover, the experimental results of Bouaziz as modeled by Massart et al. [31] has shown that YS/UTS ratio is quite high in ultra fine grained steels. In accordance with a number of earlier observations it is taken that YS/UTS commonly ranges between 0.8 and 0.85 ; taking a value 
of 0.8 the attainable estimated yield strength of the present steel should be about 1.4GPa. This value is higher than the maximum Y.S computable from consideration of grain size effect and friction stress.

Preceding discussion hints that the average YS of the steel due to ferrite grain refinement is around 1.1 GPa (average of different results). Thus an excess of 0.3-0.4 GPa is expected to be the contribution from precipitation hardening due to presence of nanoscale cementite and copper along with dispersed carbon particles (less than a nanometer size) in the microstructure. In general, ferrite of grain size around one micron shows the YS of around $900 \mathrm{MPa}$ [36] whereas cementite precipitation can enhance the strength by no less that $200 \mathrm{MPa}$ [37]. Moreover, the effect of copper in strengthening steel is quite substantial and is more than $200 \mathrm{MPa}$ in low carbon microalloyed steels [38-40]. So the additional contribution by precipitation hardening enhances the achievable values of YS. Hence, on account of excellent YS and UTS of the experimental steel (1.4 GPa and $1.8 \mathrm{GPa}$ respectively), it is inferred that the steel can be gainfully employed in various applications. Practical application of such high strength MA steel has already taken off and it is expected that with some more technological input, the reported material can emerge as an attractive functional material.

\section{Conclusion}

Fine grained steel with average grain size of 0.70 micron was successfully synthesized by a novel technique of mechanical alloying of AC with mechanically alloyed iron and copper powder. The steel shows a microhardness value higher than many similar ultra-fine grained steels produced by different processes. The excellent hardness value of this steel originates from the presence of nanoscale precipitates of $\mathrm{Fe}_{3} \mathrm{C}$ and copper in an ultrafine grained ferrite matrix. The abundance of angstrom level carbon dots within the same microstructure has exerted positive effect on the property of steel. If the yield and ultimate tensile strength are computed from the observed hardness value, in accordance with the experience of the previous researchers, it would appear that the YS and UTS values of $1.4 \mathrm{GPa}$ and $1.8 \mathrm{GPa}$ respectively are seemly attainable in the presently developed steel.

Acknowledgements We would like to acknowledge MNIT, Jaipur for giving us the opportunity and funding required for this research. We are highly grateful to Materials Research Centre (MRC), MNIT for providing us all the instruments needed for experimental procedure of this report.

\section{Compliance with ethical standards}

Conflict of interest The authors declare that they have no conflict interest.

Consent for publication Not applicable.

\section{References}

1. Hosseini Far AR, Mousavi Anijdan SH, Abbasi SM (2019) The effect of increasing $\mathrm{Cu}$ and $\mathrm{Ni}$ on a significant enhancement of mechanical properties of high strength low alloy, low carbon steels of HSLA-100 type. Mater Sci Eng, A 746:384-393. https:// doi.org/10.1016/j.msea.2019.01.025

2. Jiao ZB, Luan JH, Miller MK, Liu CT (2015) Precipitation mechanism and mechanical properties of an ultra-high strength steel hardened by nanoscale NiAl and Cu particles. Acta Mater 97:5867. https://doi.org/10.1016/j.actamat.2015.06.063

3. Banerjee MK, Ghosh D, Datta S (2000) Effect of composition and thermomechanical processing on the ageing characteristic of copper-bearing HSLA steel. Scand J Metall 29(5):213-223. https ://doi.org/10.1034/j.1600-0692.2000.d01-25.x

4. Halfa Hossam (2014) Recent trends in producing ultrafine grained steels. J Min Mater Charact Eng 02(05):428-469. https ://doi.org/10.4236/jmmce.2014.25047

5. Datta S, Banerjee PS, Banerjee MK (2004) Effect of thermomechanical processing and aging on microstructure and precipitation hardening in low carbon Cu-B steel. Ironmak Steelmak 31(4):312-318. https://doi.org/10.1179/030192304225018226

6. Banerjee MK, Banerjee PS, Datta S (2001) Effect of thermomechanical processing on the microstructure and properties of a low carbon copper bearing steel. ISIJ Int 41(3):257-261. https:// doi.org/10.2355/isijinternational.41.257

7. Semenova IP, Modina JM, Polyakov AV, Klevtsov GV, Klevtsova NA, Pigaleva IN, Valiev RZ, Langdon TG (2018) Fracture toughness at cryogenic temperatures of ultrafine-grained Ti-6Al-4V alloy processed by ECAP. Mater Sci Eng, A 716:260-267. https:// doi.org/10.1016/j.msea.2017.12.106

8. Fukuda Y, Oh-ishi K, Horita Z, Langdon TG (2002) Processing of a low carbon steel by equal channel angular pressing. Acta Mater 50:1359-1368. https://doi.org/10.1016/S1359-6454(01)00441-4)

9. Zhang L, Huang X, Wang Y, Guo Y, Dai G, Li D et al (2018) Achieving excellent strength-ductility and impact toughness combination by cyclic quenching in medium Mn TRIP-aided steel. J Mater Eng Perform 27(11):5769-5777. https://doi.org/10.1007/s1166 5-018-3662-6

10. Sun L, Muszka K, Wynne BP, Palmiere EJ (2014) Effect of strain path on dynamic strain-induced transformation in a microalloyed steel. Acta Mater 66:132-149. https://doi.org/10.1016/j. actamat.2013.11.062

11. Beladi H, Kelly GL, Shokouhi A, Hodgson PD (2004) The evolution of ultrafine ferrite formation through dynamic strain induced transformation. Mater Sci Eng, A 371:343-352. https://doi. org/10.1016/j.msea.2003.12.024

12. Hao L, Sun M, Xiao N, Li D (2012) Characterizations of dynamic strain-induced transformation in low carbon steel. J Mater Sci Technol 28(12):1095-1101. https://doi.org/10.1016/S1005 $-0302(12) 60178-9$

13. Jafarian $\mathrm{H}$ (2016) Characteristics of nano/ultrafine-grained austenitic TRIP steel fabricated by accumulative roll bonding and subsequent annealing. Mater Charact 114:88-96. https://doi. org/10.1016/j.matchar.2016.02.012 
14. Yu H, Tieu K, Lu C (2014) Advanced rolling technologies for producing ultrafine-grain/nanostructured alloys. Procedia Eng 81:96-101. https://doi.org/10.1016/j.proeng.2014.09.133

15. Agarwal N, Chaudhari GP, Nath SK (2014) Slurry and cavitation erosion of HSLA steel processed by warm multidirectional forging and inter-critical annealing. Tribol Int 70:18-25. https://doi. org/10.1016/j.triboint.2013.09.017

16. Łyszkowski R, Czujko T, Varin RA (2017) Multi-axial forging of $\mathrm{Fe}_{3} \mathrm{Al}$-base intermetallic alloy and its mechanical properties. J Mater Sci 52(5):2902-2914. https://doi.org/10.1007/s1085 3-016-0584-2

17. Kumar P, Banerjee MK, Hodgson P, Choudhray AR (2017) Study of dynamic re-crystallization and copper precipitation of low carbon steel in single hit and double hit plain strain compression. Mater Today Proc 4:9509-9513. https://doi.org/10.1016/j. matpr.2017.06.214

18. Schmitt J-H, lung $T$ (2018) New developments of advanced highstrength steels for automotive applications. C R Phys 19(8):641656. https://doi.org/10.1016/j.crhy.2018.11.004

19. Kumar A, Pandel U, Banerjee MK (2018) Development of a novel MWCNT reinforced iron matrix Nanocomposite through powder metallurgy route. Powder Technol 331:41-51. https://doi. org/10.1016/j.powtec.2018.03.009

20. Kumar A, Pandel U, Banerjee MK (2017) Effect of high energy ball milling on the structure of iron-multiwall carbon nanotubes (MWCNT) composite. Adv Mater Res 6(3):245-255. https://doi. org/10.12989/amr.2017.6.3.245

21. Suh JY, Bae DH (2013) Mechanical properties of Fe-based composites reinforced with multi-walled carbon nanotubes. Mater Sci Eng, A 582:321-325. https://doi.org/10.1016/j. msea.2013.06.057

22. Munir KS, Qian M, Li Y, Oldfield DT, Kingshott P, Zhu DM, Wen C (2015) Quantitative analyses of MWCNT-Ti powder mixtures using raman spectroscopy: the influence of milling parameters on nanostructural evolution. Adv Eng Mater 17(11):1660. https ://doi.org/10.1002/adem.201500142

23. Sharma P, Kumar P, Banerjee MK (2018) Structural evolution in mechanically alloyed and spark plasma sintered iron- $0.15 \mathrm{wt} \%$ MWCNT composite. J Mater Eng Perform 27(9):4740-4748. https ://doi.org/10.1007/s11665-018-3547-8

24. Wright WJ, Askeland DR (2018) The science and engineering of materials, 7 th edn. Nelson Education, Toronto. ISBN 1-305-07676-1

25. Khanchandani H, Banerjee MK (2018) Heavy deformation of patented near-eutectoid steel. J Mater Eng Perform. https:// doi.org/10.1007/s11665-017-3081-0

26. Tohidi AA, Ketabchi M, Hasannia A (2013) Nanograined Ti-Nb micro alloy steel achieved by accumulative roll bonding (ARB) process. Mater Sci Eng, A 577:43-47. https://doi.org/10.1016/j. msea.2013.04.025

27. Ravi Chandran KS (2019) A new exponential function to represent the effect of grain size on the strength of pure iron over multiple length scales. J Mater Res. https://doi.org/10.1557/ jmr.2019.11

28. Cottrell AH (1958) Theory of brittle fracture in steel and similar metals. Trans Metall Soc AIME 212:192

29. Li JCM (1963) Petch relation and grain boundary sources. Trans Metall Soc AIME 227:239-247

30. Bouaziz $\mathrm{O}$ (2010) The ductilities in single phase steels from usual to nano-scale microstructures. Mater Sci Forum 633-634:205

31. Massart TJ, Pardoen T (2010) Strain gradient plasticity analysis of the grain-size-dependent strength and ductility of polycrystals with evolving grain boundary confinement. Acta Mater 58:5768-5781

32. Hidaka H, Tsuchiyama T, Takaki S (2001) Relation between microstructure and hardness in $\mathrm{Fe}-\mathrm{C}$ alloys with ultra fine grained structure. Scripta Mater 44:1503-1506

33. Evans $M-H$ (2012) White structure flaking (WSF) in wind turbine gearbox bearings: effects of 'butterflies' and white etching cracks (WECs). Mater Sci Technol 28(1):3-22

34. Kimura Y, Takaki S (1995) Microstructural changes during annealing of work-hardened mechanically milled metallic powders (overview). Mater Trans, JIM 36(2):289-296

35. Eckert J, Holzer JC, Krill CE, Johnson WL (1992) Reversible grain size changes in ball-milled nanocrystalline Fe-Cu alloys. J Mater Res 7(8):1980-1983

36. Najafizadeh A, Jonas JJ, Yue S (1992) Grain refinement by dynamic recrystallization during the simulated warm-rolling of interstitial free steels. Metall Mater Trans A 23(9):2607-2617

37. Jia N, Shen YF, Liang JW, Feng XW, Wang HB, Misra RDK (2017) Nanoscale spheroidized cementite induced ultrahigh strengthductility combination in innovatively processed ultrafinegrained low alloy medium-carbon steel. Sci Rep 7:2679. https ://doi.org/10.1038/s41598-017-02920-9

38. Banerjee MK, Banerjee PS, Datta S (2005) Forming processing and thermomechanical treatment-effect of thermomechanical processing on the microstructure and properties of a low carbon copper bearing steel. ISIJ Int Iron Steel Inst Jpn 41(3):257-261

39. Datta S, Banerjee PS, Banerjee MK (2004) Effect of thermomechanical processing and ageing on microstructure and precipitation hardening in a low carbon Cu-B steel. Ironmak Steelmak 31:312-318

40. Datta S, Ghosh D, Banerjee MK (2000) Effect of composition and thermomechanical processing on the ageing characteristic of copper bearing HSLA steel. SJM Sweden 29(5):213-223

Publisher's Note Springer Nature remains neutral with regard to jurisdictional claims in published maps and institutional affiliations. 